Témoigner Témoigner. Entre histoire et mémoire

Getuigen Revue pluridisciplinaire de la Fondation Auschwitz

$122 \mid 2016$

Révisionisme et négationisme

\title{
The Railway Man: haat, waar is uw overwinning?
}

The Railway Man : Haine, quelle est ta victoire?

\section{Erik Machielsen}

Traducteur : Gorik de Henau

\section{(2) OpenEdition}

\section{Journals}

Édition électronique

URL : https://journals.openedition.org/temoigner/4088

DOI : $10.4000 /$ temoigner.4088

ISSN : 2506-6390

Éditeur :

Éditions du Centre d'études et de documentation Mémoire d'Auschwitz, Éditions Kimé

Édition imprimée

Date de publication : 2 mai 2016

Pagination : 24-27

ISSN : 2031-4183

Référence électronique

Erik Machielsen, «The Railway Man: haat, waar is uw overwinning?», Témoigner. Entre histoire et mémoire [Online], 122 | 2016, Online op 30 septembre 2021, geraadpleegd op 03 janvier 2022. URL: http://

journals.openedition.org/temoigner/4088; DOI: https://doi.org/10.4000/temoigner.4088 


\section{THE RAILWAY MAN: HAAT, WAAR IS UW OVERWINNING?}

FILM The Railway Man is het waargebeurde verhaal van een man die werd gemarteld tijdens de oorlog in de Stille Oceaan en verneemt dat zijn beul nog in leven is. De film gaat over wraak, vergeving, empathie en nog veel meer. Het hoofdpersonage wordt schitterend vertolkt door Colin Firth, die in 2011 met The King's Speech een Oscar won.

V eertigjaar later is de man nog altijd getekend door wat hij in 1942 te verduren kreeg. Hij werkte toen mee aan de bouw van een spoorwegennet en de bijbehorende brug die later beroemd werd dankzij een film, namelijk die over de rivier Kwai. The Railway Man is losjes gebaseerd op een boek; om de aandacht gaande te houden en wat spanning op te bouwen veroorlooft hij zich enkele melodramatische vrijheden, maar zonder zelfgenoegzaamheid. Bovendien wordt een en ander afgezwakt door het spel van de acteurs. Het thema van de getraumatiseerde en vaak ook verstoten soldaat keert regelmatig terug in de cinema, van Johnny Got His Gun via The Deer Hunter, Rambo: First Blood (afgekeken van Ruckus, een B-film die twee jaar eerder was uitgekomen), Birdy en Born on the Fourth of July tot American Sniper. Ook het thema wraak komt vaak aan bod in films die doorgaans minder tot denken aanzetten en waarin actie voorrang krijgt op reflectie. Ze zijn voor het grote publiek bestemd, doen een beroep op uiteenlopende genres en sfeertjes, en vervallen soms in het karikaturale. Onderwerpen zijn: oorlogsmisdaden (Inglourious Basterds van Quentin Tarantino), Jan met de pet die zijn rekeningen vereffent (Charles Bronson in de Death Wish-reeks van Michael Winner, J. Lee Thompson en Allan A. Goldstein), de cowboy die wraak neemt voor het uitmoorden van zijn gezin (Once Upon a Time in the West), Michel Duchaussoy in Que la bête meure van

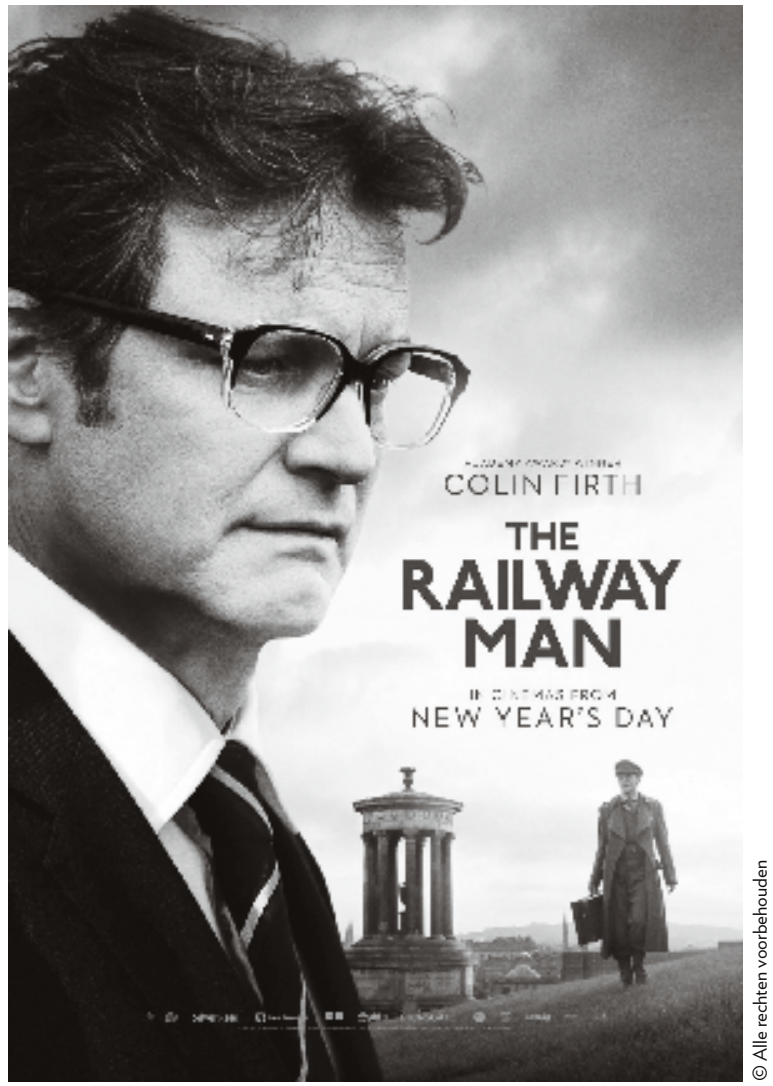

Claude Chabrol, Batman die Gotham City beschermt tegen de moordenaar van zijn ouders. Wat The Railway Man van die films onderscheidt, is dat hij niet wraak maar juist vergeving, en ook de vraag om vergeving, als centraal thema naar voren schuift. Een niet onbelangrijke nuance in een maatschappij waar vergeving wordt omgezet in een aantal dagen gevangenis. Dat geeft soms aanleiding tot situaties waarbij iemand die zijn schuld heeft betaald je recht in de ogen kijkt en verkondigt: 'Ik heb betaald, ik hoef geen vergiffenis te vragen.' 


\section{NOODLOTTIGE TREIN}

We schrijven 1980, Berwickupon-Tweed in Engeland. Een man doorbladert een boek en weidt uit over treintrajecten en uurregelingen. Hij vertelt aan zijn vrienden hoe hij een trein naar Glasgow had genomen omdat zijn trein vertraging had, waardoor hij een andere trein kon inhalen, waarmee hij weer de goede richting uitging. Terwijl hij een en ander aan de controleur uitlegt, wekt hij de nieuwsgierigheid van de passagierster tegenover hem. In het daaropvolgende gesprekpronkt hij met zijn kennis en schetst de geschiedenis van elke stad waar de trein langsrijdt. Vanaf het begin demonstreert Colin Firth zijn grote acteertalent: alleen al met zijn blik geeft hij gestalte aan zijn personage. In zijn ogen is verdriet te lezen dat niet het gevolg is van een auto-ongeval of het verlies van een geliefde. Nee, je kunt er de oorlog in zien... Hij is Eric Lomax, het personage heeft bezit genomen van de acteur. Nauwelijks staat hij op het perron en vertrekt de trein of Lomax moet toegeven dat hij verliefd is. Het voorwerp van die abrupte affectie is Patricia (Patti) Wallace, een voormalige verpleegster die hij zal terugzien en huwen. Ondanks de idyllische sfeer en de zoetgevooisde gevoelens waarschuwt hij haar dat hij niet grappig is. En met reden.

\section{DEMONEN UIT HET VERLEDEN}

Na de huwelijksnacht komt een als soldaat uitgedoste Japanner hem wekken. Hij gelast hem op te staan en hem te volgen, met alleen zijn nachthemd aan, tot buiten het hotel in een Thais bos. Ze gaan het portiek van een fort binnen en daar bevinden zich mannen in kooien of opgehangen aan hun handen. Hij wordt naar een klein vertrek gebracht aan het eind van een weggetje. Het vooruitzicht vervult hem met afschuw en hij begint te smeken, maar niets aan te doen, hij wordt in het lokaal geworpen. Verlamd door angst en schreeuwend kronkelt hij over het parket van zijn hotelkamer. Patti komt eraan; ze is verrast, van haar stuk gebracht, verontrust. Het was een nachtmerrie. Vanaf dan zoekt Lomax het isolement; hij hult zich in stilzwijgen en wordt vaak gekweld door beangstigende beelden - alleen op het strand, zittend op zijn bed met starre blik terwijl zijn vrouw slaapt, slaapwandelend. Als Patricia hem vraagt wat er aan de hand is, wordt hij onbuigzaam en zelfs onhandelbaar. Hij laat zich gaan, betaalt de facturen niet meer. Dan vindt Patricia in zijn bureau een schrift vol schetsen van uitgemergelde, mishandelde wezens in wat wel een kamp lijkt. De gerechtsdeurwaarders komen eraan en plaatsen Patti voor een voldongen feit, want ze willen een inventaris opmaken van hun goederen om ze in beslag te nemen. Lomax hoort het aan, staat op, houdt de deurwaarders voor de vijand - hij is in de greep van het visioen van het bewuste lokaal, waar altijd dezelfde Japanse soldaat uitkomt - en valt hen aan met een breekmes. Dat is de spreekwoordelijke druppel. Patti botst tegen de muur van stilte van haar man, die duidelijk behoefte heeft aan de hulp die hij afwijst. Ze begeeft zich naar de club waar hij andere veteranen pleegt te ontmoeten, onder wie een zekere Finlay. Aan hem vraagt ze de stilte te doorbreken waarmee hij en zijn soortgenoten zich omringen, want op die manier maken ze niet alleen hun eigen leven tot een hel, maar ook dat van de mensen in hun omgeving. Het is een stilte die te begrijpen valt, want de gruwel was zo erg dat de meeste slachtoffers er heilig van overtuigd zijn dat niemand hen zal geloven. En het loochenen van hun leed is een ondraaglijke gedachte. Ontroerd door Patricia's gebaar stemt $\bullet \bullet$ 
•. Finlay - de krachtige Stellan Skarsgård, in het westen bekend geworden via Lars von Triers Breaking the Waves - ermee in om de geheimhouding op te heffen.

\section{HEL OP AARDE}

In 1942 worden de Engelse soldaten tot overgave gedwongen en ze verlaten Singapore. De Japanse soldaten drijven hen als vee bijeen in treinwagons en vervoeren hen zonder eten of drinken naar Thailand. Bevelen worden met geweld uitgebraakt, smekende armen worden met geweerkolven neergeslagen. De gevangenen worden in het oerwoud van de trein gehaald en naar een modderige bouwwerf gebracht, waar ze een apocalyptisch schouwspel te zien krijgen: uitgemergelde mensen zwoegen als zombies en worden zonder pardon gegeseld als het tempo verslapt. Lomax is het gewend tijd en plaats bij te houden en heeft de haltes van de tocht naar het kamp gememoriseerd. Hij tekent een plan zodat hij kan bepalen waar hij zich bevindt, namelijk in Kanchanaburi, wat wordt bevestigd als een Japanner zegt dat de rivier die op die plek stroomt de Kwai is. Om het moreel van hemzelf en zijn kameraden op te krikken knutselt hij in het geheim een radio in elkaar, waarmee hij naar de BBC luistert. Zo verneemt hij dat de geallieerden oprukken in Afrika, dat de Russen Stalingrad hebben terugveroverd, dat Duitsland wordt gebombardeerd. Maar de plannen die Lomax in een bamboestok had verstopt worden ontdekt. Onmiddellijk worden vier mannen opgetrommeld, onder wie Lomax. Zonder reden wordt een van hen met een slaghout afgetuigd terwijl de anderen in de houding moeten toekijken. Lomax treedt naar voren, neemt zijn bril af en bekent dat hij de radio heeft gebouwd. Zo begint zijn marteling, een regelrecht bloedbad, in het zicht van de gevangenen.

Een week verstrijkt, waarin zijn vrienden trachten hem te verzorgen. Maar het is nog niet voorbij, want de Japanners keren terug. Hij heeft veel bloed verloren en zijn polsen zijn gebroken. In die toestand, blootsvoets, doen ze hem rennen achter een motorfiets, waaraan hij met een touw is vastgemaakt. Twee weken lang verdwijnt hij. Tegenover zijn vrienden zal hij nooit bekennen wat hij heeft doorstaan. In werkelijkheid werd hij ondervraagd door de Kempeitai, de militaire politie - zeg maar de Gestapo - van het Japanse keizerlijke leger. Maar de man die in zijn geheugen staat gegrift is de vertaler Takashi Nagase, die zijn opdracht te buiten gaat en zich wreder en achterdochtiger toont dan de ondervragers.

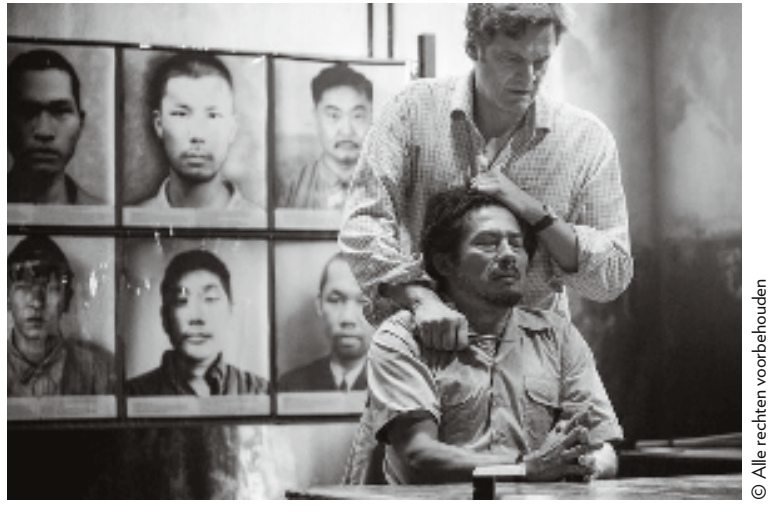

De marteling van Lomax wordt getoond, maar zonder er plezier in te scheppen en zonder nadruk, wat een van de verdiensten is van de Australische regisseur Jonathan Teplitzky. Hij weegt de gevolgen van het geweld af, dit in tegenstelling tot het ongezonde voyeurisme dat tegenwoordig de trend zet en waarbij het geweld wordt aanschouwd zonder er aanstoot aan te nemen. De film wordt er eens zo krachtig door.

Dan komt het moment, weer in de jaren 1980, waarop alles omslaat. Lomax verneemt dat Nagase nog in leven is. Moet hij, om zijn demonen uit te drijven, nu de man uitschakelen die er de oorzaak van is? Via een wanhoopsdaad verplicht Finlay hem om die vraag onder ogen te zien en vooral om ze te beantwoorden. Gewapend met een mes trekt Lomax naar Thailand. Daar ziet hij hoe de bron van zijn lijden toeristen rondleidt in een herdenkingsmuseum. Zodra ze zijn vertrokken confronteert Lomax Nagase, die hem herkent. Hij vindt een man die is getekend door het kwaad waaraan hij medeplichtig is en die sindsdien al tientallen jaren boete doet. Een man die niet wil dat de oorlogstragedie in de vergetelheid raakt. Een man die zich inzet voor verzoening, waardoor hij wat rust vindt in zijn leven. En tot slot een man die de straf wil aanvaarden die Lomax voor hem heeft bedacht.

\section{DE WAARHEID GELOGEN}

De film is gebaseerd op een boek van Eric Lomax. Die ontmoette de acteurs en was aanwezig op de set, maar overleed tijdens de montage. Lomax gaf dus zijn goedkeuring voor een aantal vrijheden die de regisseur nam met de film: zo wordt meer aandacht besteed aan het personage van Patricia en komt de nadruk te liggen 


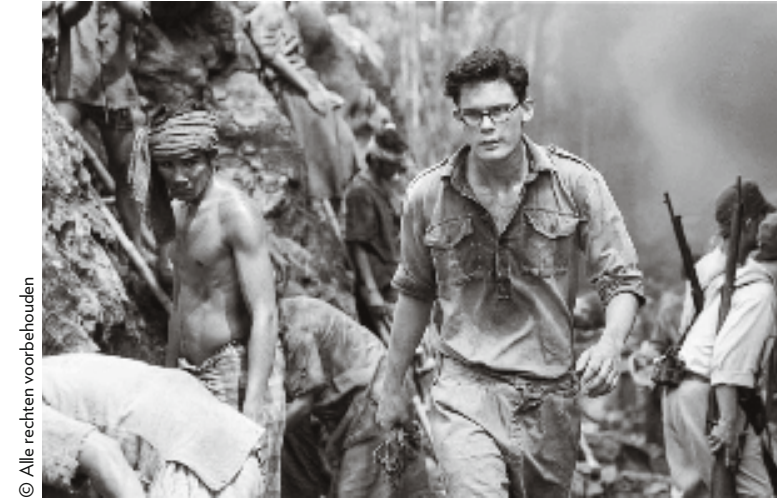

op de hindernissen die de liefde overwint. Lotgenoot Finlay heeft dan weer nooit bestaan. Hij werd wel geïnspireerd door Jim Bradley, een van Lomax' vrienden, maar pleegde niet de wanhoopsdaad die op een bepaald moment in de film wordt vermeld. Anderzijds toont niet Bradley, maar diens vrouw Lindy aan Lomax de fotokopie van een artikel waar een foto van zijn beul bijstaat.

Behalve in The Bridge on the River Kwai komt het onderwerp van de film in Groot-Brittannië maar zelden aan bod, in publicaties, op school of in de krant. Natuurlijk is de Engelse overgave in Singapore niet bepaald een glorierijke episode. Churchill omschreef ze ooit als 'de grootste militaire ramp in de geschiedenis van het Britse rijk'. We stellen ook een paar chronologische aanpassingen vast. Zo ontmoetten Lomax en Patricia elkaar in 1980 en ze huwden in 1983. En Lomax hoorde pas in 1993 van het bestaan van Takashi Nagase en ontmoette hem twee jaar later. Die ontmoeting vond niet plaats zonder medeweten van Nagase. Daartoe aangezet door zijn vrouw had Lomax hem eerst geschreven. En het gesprek vond niet plaats in intieme kring, maar in het bijzijn van een televisieploeg; de documentaire Enemy, My Friend? is daarvan het resultaat.

We mogen dan in spanning zitten, maar we moeten opnieuw vaststellen hoe oordeelkundig de casting van de acteurs wel is. Net als Colin Firth is de acteur die Nagase vertolkt op zijn plaats. Het gaat om Hiroyuki Sanada, te zien in de televisieserie Lost en recenter nog in Mr. Holmes aan de zijde van Ian McKellen. Zijn terughoudende vertolking stoelt op blikken, gebaren, het vel van zijn gezicht dat klopt op het ritme van zijn hartslag. Ze is zo opmerkelijk dat we zelfs mededogen opvatten voor zijn personage. Voor Patricia Wallace liet Teplitzky zijn keuze vallen op Rachel Weisz. Maar die zag zich verplicht op de set te blijven van het door vertragingen geplaagde Jason Bourne: The Legacy. Op aanraden van Firth werd ze vervangen door Nicole Kidman, die verbluffend blijkt. Nog een acteur die door Firth werd aangeraden is Jeremy Irvine. De ster van War Horse - een van Spielbergs films die het minst in het laatje brachten, ondanks zes Oscarnominaties (onder meer voor de bestefilm) in 2012 - speelt dejonge Lomax. Hij lijkt zo sterk op zijn personage dat Charmaine, Eric Lomax' dochter, helemaal van streek was toen ze hem ontmoette. Voor deze rol vermagerde hij vijftien kilo, de prijs die hij moest betalen om gestalte te kunnen geven aan Lomax zoals die eruitzag na zijn perioden van eenzame opsluiting.

\section{LIEFDE OF HAAT?}

Het emotionele einde is het enige moment dat de film gaat slepen, maar melodramatisch wordt het niet. Ook hier weer geeft de regisseur blijk van pudeur. Je kunt het geen happy end noemen, daarvoor is het onderwerp te ernstig. Maar je vraagt je wel af hoe je zelf zou hebben gereageerd, waardoor we onze kleine zorgen gaan relativeren naast die van de twee protagonisten. Zijn we in staat om, al is het maar in het leven van elke dag, de kleingeestigheden te vergeven waarmee we te maken krijgen, te verzaken aan de vijandigheden die ons petje te boven gaan en vergiffenis te schenken aan de daders ervan? Is menslievende wijsheid de oplossing of wordt daardoor net een precedent geschapen, waardoor je de deur voor herhaling op een kier zet? Is boetedoening mogelijk? Brengt vergeving werkelijk redding? Op die vraag gaf Nelson Mandela volgend antwoord: 'Door vergeving wordt de ziel bevrijd en angst tenietgedaan. Daarom is ze zo'n krachtig wapen.' Een antwoord dat wel dat van Eric Lomax waard is: 'Ooit moet de haat stoppen.' Een citaat dat in vergulde letters op de grafsteen van zijn auteur staat, die op 8 oktober 2012 overleed.

Erik Machielsen Vertaling: Gorik de Henau

\section{Meer weten}

The Railway Man van Jonathan Teplitzky (2013). Met Colin Firth (Eric Lomax), Nicole Kidman (Patricia Wallace), Stellan Skarsgärd (Finlay), e.a. - 116 minuten. 